\title{
A Systematic Review of Domains, Techniques, Delivery Modes and Validation Methods for Intelligent Tutoring Systems
}

\author{
Aized Amin Soofi ${ }^{1}$, Moiz Uddin Ahmed ${ }^{2}$ \\ Department of Computer Science \\ Allama Iqbal Open University, Islamabad, Pakistan
}

\begin{abstract}
An Intelligent Tutoring System (ITS) is a computer software that help students in learning educational or academics concepts in customized environment. ITSs are instructional systems that have capability to facilitate user by providing instantaneous feedback and instructions without any human intervention. The advancement of new technologies has integrated computer based learning with artificial intelligence methods with aim to develop better custom-made education systems that referred as ITS. One of the important factors that affect students learning process is self-learning; all students cannot have similar experience of learning scholastic concepts from same educational material. Because students have individual differences that make some topics difficult or easy to understand regarding taken subjects. These systems have capability to improve teaching and learning process in different educational domains while respecting individual learning needs. In this study an attempt is made to review the research in field of ITSs and highlight the educational areas or domains in which ITSs have been introduced. Techniques, delivering modes and evaluation methodologies that have been used in developed ITSs have also been discussed in this work. This work will be helpful for both academia and new comers in the field of ITSs to further strengthen basis of tutoring systems in educational domains.
\end{abstract}

Keywords-ITS; intelligent tutoring system; intelligent learning; adaptive learning; intelligent tutoring; ITS review

\section{INTRODUCTION}

Information and communication technologies (ICT) have become necessary part of educational system in order to replace traditional teaching system with modern teaching system [1]. Modern information resources like hypermedia, multimedia, internet and intranet are contributed together to provide advanced learning pedagogies [2-4]. The new educational model is learner centered model in which flexibility is provided to learner to learn according to their ability and requirements in simple words this new model is oriented toward learner or student $[5,6]$. To increase efficiency of these learning model factors like adaptability, interactivity, intelligence and dynamically generated web contents are added to these models that leads them towards development of intelligent tutoring system (ITS).

Many factors have been highlighted in previous studies that reflect importance of ITSs in educational domain, such as time limitations and individual meeting with students make it difficult for teacher for provide feedback to individual student in large class [7]. In private tutoring system, usually tutor provide help to student as much as he/she can but providing as many tutors to facilitate number of students is not feasible option from economic point of view [8]. ITSs are a solution that can solve these kind of problems in education. The most important feature of ITSs is their ability to customize instructional strategies and activities according to learner's requirements and characteristics $[9,10]$. Many researchers contribute their efforts for refining student's ability to solve different problems in education [11-14]. The first ITS named SCHOLAR tutor was introduced in 1970 [15]. This system was developed to review student's knowledge about South America geography. SCHOLAR tutor began two way interaction with students by using facts of knowledge and semantic network of concepts to appraise student's knowledge in geography [16].

The traditional ITSs consist of four main modules i.e. expert module, student or learner module, pedagogical or tutor module and user interface module [17]. The expert module deals with domain knowledge that learner or student wants to learn [18]. The methods for problem solving and evaluating students activities in learning process are also considered in this module [19]. The student module completely depends on student attributes such as learning style, activities, behavior and knowledge deficiency. All relevant information about student is gathered and updated in system to refine learning process [20]. Additional information such as past learning experiences and learning preferences may also be stored in system to provide adaptability in teaching process [10].

The pedagogical module identifies students deficiencies in specific topic or subject based on learner module and focus on the strategies to provide best material that overcome the deficiencies of student in specific area or subject or topic [21]. The user interface module is communication part of the ITS it provides interaction facility between system and user [22]. The aim of present study is to review the developed ITSs across educational fields and gather comprehensive information about their development techniques, purpose, delivery modes and evaluation methods. This paper is organized as following; in section II methodology of review is presented, results are presented in section III. The answers of posed questions are discussed in sub sections of section III and work is concluded in section IV. 


\section{MethodOLOGY}

One of the most common ways to evaluate and understand all available research literature related to specific research problem or question is systematic literature review. In literature, numbers of methodologies are available for systematic review. The methodology adopted for this systematic literature review was based on guidelines presented in [23]. The review process consists of three phases which contain ten sub activities. The details of activities conducted in these phases are shown in Fig. 1 and discussed under.

In first phase of review the following questions were posed:

Q1: What are the subjects or domains for which ITSs have been designed?

Q2: What types of techniques or tools have been used in development of ITSs?

Q3: What type of delivery modes have been used by developed ITSs?

Q4: How the techniques have been validated?

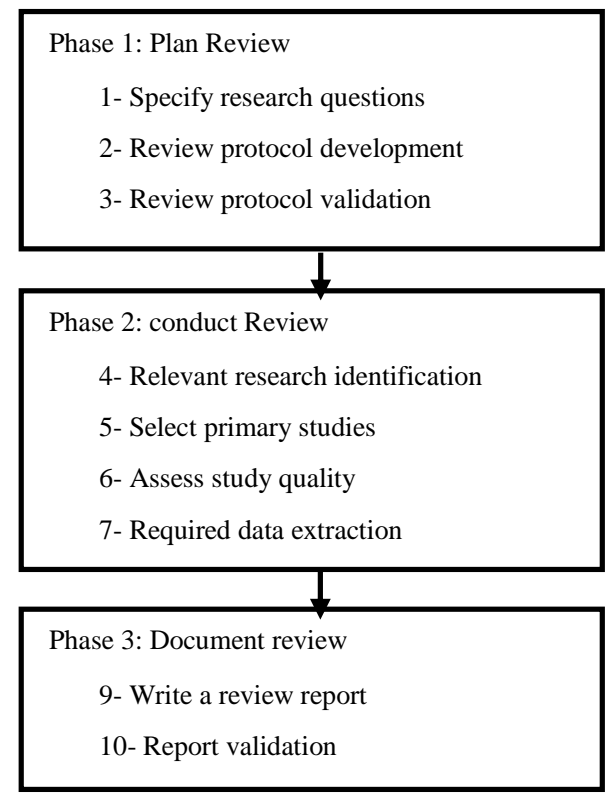

Fig. 1. Review Process Adapted from [23].

TABLE I. REVIEW PROTOCOL

\begin{tabular}{|l|l|l|}
\hline Year & Sources & Keywords \\
\hline 2014-2018 & $\begin{array}{l}\text { IEEE Xplore, science direct, } \\
\text { google scholar, ACM portal } \\
\text { digital library, springer }\end{array}$ & $\begin{array}{l}\text { ITS, intelligent tutoring } \\
\text { system, intelligent learning, } \\
\text { adaptive learning, } \\
\text { intelligent tutoring, ITS } \\
\text { review }\end{array}$ \\
\hline
\end{tabular}

The questions were formulated in order to complete first sub activity of phase 1 . In second sub activity of phase 1 a review protocol was developed. The review protocol includes considered time span of published papers, publication sources and keyword used to find required data. The research focus on the articles published in last five years and repositories used to find out required data include IEEE xplorer, science direct, ACM, Google scholar, springer and web of science. The final review protocol is given in Table I. The developed protocol is reviewed and validated after making some necessarily changes by researchers.

The execution of search chain on selected sources provides us a set of 82 articles. These articles were screened on basis of their title and abstract. After initial review according to inclusion criteria these 82 articles were filtered and only 39 articles were left that meet our inclusion criteria. For strengthen the search related to relevant articles, backward snowballing guidelines presented in [24] was also adopted to find out cited papers in selected articles that meet our inclusion criteria; this was done to make sure that no articles related to our research questions were left to considered.

In second phase of review a literature search was conducted in pre-defined databases by using keywords mention in Table I. These keywords were used in combination and alone for initial collection of research material related to our specified research questions. The inclusion criteria of this study is strictly based on posed research questions. Only those articles that contain material related to our research question were considered in this review.

\section{RESULTS}

The results of review are presented in this section. A year wise representation of results is given in Table II. These results are characterized with research questions posed earlier in this study. The variables of selected studies are presented in Table III.

\section{A. What are the Subject/Domains for which ITSs have been Designed?}

The result of review Table IV shows educational domains for which ITS have been designed. The frequency of each educational field in selected papers is demonstrated in Fig. 2. These domains were divided into six basic categories include; computer science, health/ medical science, mathematics, physics, language and others. Computer science was leading field in which ITS have been widely used to provide help in learning process. In computer science, programming was major area in which these systems were used. The frequency of systems that were designed for programming purposes in computer science domain was $61.11 \%$. Majority of the users of these systems were university level students.

TABLE II. YEAR WiSE SEARCH RESUlTS

\begin{tabular}{|l|l|}
\hline year & No. of papers \\
\hline 2014 & 7 \\
\hline 2015 & 8 \\
\hline 2016 & 6 \\
\hline 2017 & 8 \\
\hline 2018 & 10 \\
\hline Total & 39 \\
\hline
\end{tabular}


TABLE III. VARIABLES OF SELECTED PAPERS

\begin{tabular}{|c|c|c|c|c|c|c|}
\hline $\begin{array}{l}\text { Publication } \\
\text { year }\end{array}$ & Title & domain & purpose & Technique/tools & Delivery mode & Validation \\
\hline 2018 & [8] & computer science & $\begin{array}{l}\text { Problem solving in } \\
\text { computer } \\
\text { programming }\end{array}$ & $\begin{array}{l}\text { Bayesian network \& multi agent } \\
\text { system }\end{array}$ & Web based & $\begin{array}{l}\text { Experimental study } \\
\text { (comparison between } \\
\text { groups) }\end{array}$ \\
\hline 2018 & [25] & mathematics & $\begin{array}{l}\text { Personalization } \\
\text { algebra teaching }\end{array}$ & $\begin{array}{l}\text { Cognitive Tutor Algebra (CTA), } \\
\text { Rule based }\end{array}$ & $\begin{array}{l}\text { Computer based } \\
\text { (proprietary)application } \\
\text { software }\end{array}$ & Experimental study \\
\hline 2018 & [14] & mathematics & $\begin{array}{l}\text { Modeling } \\
\text { mathematics learning }\end{array}$ & $\begin{array}{l}\text { ALEKS(Assessment and } \\
\text { LEarning in Knowledge Spaces) }\end{array}$ & Web based & Observation study \\
\hline 2018 & {$[26]$} & Others & $\begin{array}{l}\text { Find metacognitive } \\
\text { prompt in ITS }\end{array}$ & $\begin{array}{l}\text { iSTART (Interactive Strategy } \\
\text { Training for Active Reading and } \\
\text { Thinking), NLP }\end{array}$ & Web based & $\begin{array}{l}\text { Experimental study } \\
\text { (pretest and posttest) }\end{array}$ \\
\hline 2018 & {$[27]$} & computer science & teaching programming & Bayesian Network & web based & Experimental study \\
\hline 2018 & {$[28]$} & Computer science & $\begin{array}{l}\text { Enhancing object } \\
\text { oriented programing }\end{array}$ & Naive Bayes algorithm & Software prototyping & $\begin{array}{l}\text { Simulated student } \\
\text { model (prototype } \\
\text { testing) }\end{array}$ \\
\hline 2018 & [29] & Computer science & $\begin{array}{l}\text { teaching programming } \\
\text { language }\end{array}$ & $\begin{array}{l}\text { ITSB tool } \\
\text { (Delphi IDE) }\end{array}$ & $\begin{array}{l}\text { Computer based } \\
\text { application software }\end{array}$ & User feedback \\
\hline 2018 & [30] & Computer science & $\begin{array}{l}\text { Android application } \\
\text { development }\end{array}$ & Rule based reasoning & Web based & Experimental study \\
\hline 2018 & [31] & medical & $\begin{array}{l}\text { Learning platform for } \\
\text { Autism Spectrum } \\
\text { Disorder childs }\end{array}$ & $\begin{array}{l}\text { Chatbot using machine learning } \\
\text { techniques (Convolution Neural } \\
\text { Network) }\end{array}$ & Theoretical Framework & No validation \\
\hline 2018 & [32] & Computer science & $\begin{array}{l}\text { Solving multimedia } \\
\text { problems }\end{array}$ & $\begin{array}{l}\text { MyST (my science tutor), } \\
\text { Intelligent multi agents }\end{array}$ & Web based & Experimental study \\
\hline 2017 & [33] & Computer science & $\begin{array}{l}\text { Self-learning in } \\
\text { computer engineering }\end{array}$ & $\begin{array}{l}\text { Artificial Neural Network based } \\
\text { technique \& Vortex } \\
\text { Optimization Algorithm }\end{array}$ & $\begin{array}{l}\text { Computer based } \\
\text { application software }\end{array}$ & $\begin{array}{l}\text { Experimental study \& } \\
\text { user feedback }\end{array}$ \\
\hline 2017 & {$[34]$} & Others & $\begin{array}{l}\text { Engineering students } \\
\text { assessment }\end{array}$ & $\begin{array}{l}\text { Open learning environment } \\
\text { (StuDiAsE), fuzzy rule based } \\
\text { system }\end{array}$ & Web based & $\begin{array}{l}\text { Student diagnostic } \\
\text { test }\end{array}$ \\
\hline 2017 & [35] & Physics & $\begin{array}{l}\text { Teaching basic } \\
\text { electronics }\end{array}$ & $\begin{array}{l}\text { Bayesian-based } \\
\text { technique (Bayesian knowledge } \\
\text { tracing) }\end{array}$ & Proposed model & No validation \\
\hline 2017 & [36] & Computer science & Deductive logic & $\begin{array}{l}\text { Bayesian-based \& data } \\
\text { mining (classification) } \\
\text { techniques }\end{array}$ & Web based & $\begin{array}{l}\text { Experimental study } \\
\text { (learner performance) }\end{array}$ \\
\hline 2017 & [37] & Computer science & $\begin{array}{l}\text { fundamental computer } \\
\text { programming }\end{array}$ & - & Theoretical framework & $\begin{array}{l}\text { Experimental study } \\
\text { (student response) }\end{array}$ \\
\hline 2017 & {$[38]$} & medical & $\begin{array}{l}\text { Cardio metabolic risk } \\
\text { assessment }\end{array}$ & Artificial Neural Network & Web based & $\begin{array}{l}\text { Experimental } \\
\text { (Comparative analysis } \\
\text { between two groups) }\end{array}$ \\
\hline 2017 & [39] & mathematics & $\begin{array}{l}\text { Provide support in } \\
\text { basic mathematics } \\
\text { learning }\end{array}$ & $\begin{array}{l}\text { PGBM-COMPS tutor program, } \\
\text { Rule based reasoning }\end{array}$ & Theoretical framework & $\begin{array}{l}\text { Experimental } \\
\text { (pretest-posttest } \\
\text { comparison) }\end{array}$ \\
\hline 2017 & [40] & Computer science & $\begin{array}{l}\text { Teaching } \\
\text { programming } \\
\text { language }\end{array}$ & $\begin{array}{l}\text { ITSB authoring tool } \\
\text { (Delphi IDE) }\end{array}$ & $\begin{array}{l}\text { Computer based } \\
\text { application software }\end{array}$ & User feedback \\
\hline
\end{tabular}




\begin{tabular}{|c|c|c|c|c|c|c|}
\hline $\begin{array}{l}\text { Publication } \\
\text { year }\end{array}$ & Title & domain & purpose & Technique/tools & Delivery mode & Validation \\
\hline 2016 & [41] & medical & Cryosurgery prototype & $\begin{array}{l}\text { Hybrid modeling approach } \\
\text { (rules and constraints) }\end{array}$ & $\begin{array}{l}\text { Computer based } \\
\text { application software }\end{array}$ & $\begin{array}{l}\text { Experimental } \\
\text { (Comparative analysi } \\
\text { between two groups) }\end{array}$ \\
\hline 2016 & [42] & Computer science & $\begin{array}{l}\text { Platform to teach MS } \\
\text { word and PowerPoint }\end{array}$ & $\begin{array}{l}\text { Type- } 2 \text { fuzzy rule based } \\
\text { reasoning }\end{array}$ & Web based & Student performance \\
\hline 2016 & [43] & mathematics & $\begin{array}{l}\text { Mathematical } \\
\text { experiment }\end{array}$ & Bayesian technique & Web based & $\begin{array}{l}\text { Experimental study } \\
\text { (student performance } \\
\text { on different } \\
\text { conditions) }\end{array}$ \\
\hline 2016 & [44] & medical & $\begin{array}{l}\text { Understanding genetic } \\
\text { breast cancer risk }\end{array}$ & Fuzzy-Trace Theory & $\begin{array}{l}\text { Computer based } \\
\text { application software } \\
\text { (using Auto Tutor) }\end{array}$ & Experimental study \\
\hline 2016 & [45] & Computer science & $\begin{array}{l}\text { Problem solving } \\
\text { (programming) by } \\
\text { game base assessment }\end{array}$ & $\begin{array}{l}\text { Bayesian network \& multi agent } \\
\text { system }\end{array}$ & Web based & $\begin{array}{l}\text { Experimental study } \\
\text { (controlled groups) }\end{array}$ \\
\hline 2016 & [46] & language & $\begin{array}{l}\text { Teaching English } \\
\text { grammar }\end{array}$ & $\begin{array}{l}\text { ITSB authoring tool } \\
\text { (Delphi IDE) }\end{array}$ & $\begin{array}{l}\text { Computer based } \\
\text { application software }\end{array}$ & User feedback \\
\hline 2015 & [12] & Computer science & $\begin{array}{l}\text { Improve problem } \\
\text { solving skills of } \\
\text { novice programmer }\end{array}$ & $\begin{array}{l}\text { Intelligent multi agent, Bayesian } \\
\text { network and NLP algorithm }\end{array}$ & Web based & $\begin{array}{l}\text { Learner knowledge } \\
\text { (pretest and posttest) } \\
\& \text { performance }\end{array}$ \\
\hline 2015 & [47] & medical & $\begin{array}{l}\text { Human circulatory } \\
\text { and emotional state }\end{array}$ & $\begin{array}{l}\text { Meta Tutor } \\
\text { (Intelligent multi agents) }\end{array}$ & web based & $\begin{array}{l}\text { Correlation between } \\
\text { emotional } \\
\text { measurement } \\
\text { methods }\end{array}$ \\
\hline 2015 & [48] & Others & $\begin{array}{l}\text { Multiple domain } \\
\text { learning }\end{array}$ & Intelligent agents & Web based & $\begin{array}{l}\text { Experimental study } \\
\text { (student performance) }\end{array}$ \\
\hline 2015 & [49] & Computer science & Slide presentation & $\begin{array}{l}\text { Feature extraction \& clustering, } \\
\text { rule based reasoning }\end{array}$ & Web based & User feedback \\
\hline 2015 & [50] & other & $\begin{array}{l}\text { Cultural awareness } \\
\text { Content delivery }\end{array}$ & Fuzzy rule based reasoning & prototype & User feedback \\
\hline 2015 & [51] & language & $\begin{array}{l}\text { Voice conversion in } \\
\text { english }\end{array}$ & rule based reasoning & Web based & $\begin{array}{l}\text { Experimental study } \\
\text { (group experiment) }\end{array}$ \\
\hline 2015 & [52] & Computer science & $\begin{array}{l}\text { Basic computer skill } \\
\text { improvement }\end{array}$ & Intelligent multi agents & Web based & $\begin{array}{l}\text { Experimental study } \\
\text { (learner knowledge } \\
\text { and performance) }\end{array}$ \\
\hline 2015 & [53] & Physics & Physics education & deep ANN \& clustering analysis & framework & Comparison study \\
\hline 2014 & {$[19]$} & Computer science & $\begin{array}{l}\text { Debugging help for } \\
\text { novice cs students }\end{array}$ & Case based reasoning & $\begin{array}{l}\text { Computer based } \\
\text { application software }\end{array}$ & $\begin{array}{l}\text { Student performance } \\
\text { (pretest and posttest) } \\
\& \text { log evaluation }\end{array}$ \\
\hline 2014 & [54] & Physics & $\begin{array}{l}\text { Automatic feedback } \\
\text { in basic electronic }\end{array}$ & $\begin{array}{l}\text { NLP based technique and rule } \\
\text { based reasoning }\end{array}$ & Web based & $\begin{array}{l}\text { User feedback \& } \\
\text { experiment (student } \\
\text { performance) }\end{array}$ \\
\hline 2014 & [55] & mathematics & $\begin{array}{l}\text { Instructional method } \\
\text { in mathematics }\end{array}$ & rule based reasoning & $\begin{array}{l}\text { Computer based } \\
\text { application software }\end{array}$ & $\begin{array}{l}\text { Proto type testing, } \\
\text { learner and teacher } \\
\text { feedback }\end{array}$ \\
\hline 2014 & [56] & mathematics & $\begin{array}{l}\text { Peer tutoring in } \\
\text { algebra }\end{array}$ & $\begin{array}{l}\text { Bayesian knowledge tracing \& } \\
\text { rule based reasoning }\end{array}$ & $\begin{array}{l}\text { Computer based } \\
\text { application software }\end{array}$ & $\begin{array}{l}\text { Student feedback \& } \\
\text { performance (pretest } \\
\& \text { posttest) }\end{array}$ \\
\hline
\end{tabular}




\begin{tabular}{|l|l|l|l|l|l|l|}
\hline 2014 & {$[57]$} & Computer science & $\begin{array}{l}\text { Analyze program in } \\
\text { PHP }\end{array}$ & Bayesian-based technique & $\begin{array}{l}\text { Computer based } \\
\text { application software }\end{array}$ \\
\hline 2014 & {$[58]$} & language & English language & $\begin{array}{l}\text { UoLmP (rule based reasoning, if } \\
\text { then rule) }\end{array}$ & Web based feedback \&
\end{tabular}

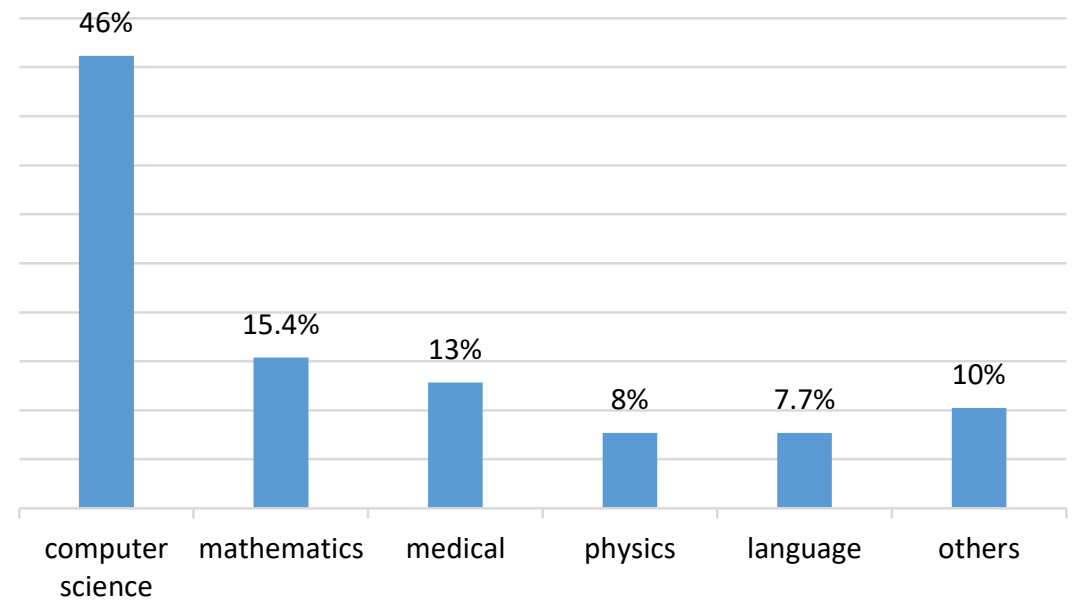

Fig. 2. Frequency of educational field in ITSs.

TABLE IV. CATEgORY Wise Results OF QUESTION 1

\begin{tabular}{|l|l|l|}
\hline Question & Category & No. of papers \\
\hline \multirow{4}{*}{$\begin{array}{l}\text { What are the subject/ } \\
\text { domains for which ITSs } \\
\text { have been designed? }\end{array}$} & Computer Science & 18 \\
\cline { 2 - 3 } & medical & 5 \\
\cline { 2 - 3 } & mathematics & 6 \\
\cline { 2 - 3 } & physics & 3 \\
\cline { 2 - 3 } & language & 3 \\
\cline { 2 - 3 } & others & 4 \\
\hline
\end{tabular}

The second major field in which ITSs were used was mathematics, majority of ITSs $(66.66 \%)$ were designed for school level students in this field to provide help in basic mathematics. The medical science field is at third rank, in which most of the system provides theoretical help to the students in understanding concepts about different topics, diseases and their management. In physics these systems were designed to provide theoretical concepts about different topics with focus on electronics. In languages domain all found ITSs were designed to teach English language or grammar.

\section{B. What Type of Techniques or Tools have been used in Development of ITSs?}

The review results of question 2 are presented in Table $\mathrm{V}$ and frequency of techniques used in development of tutoring systems is showed in Fig. 3. The techniques used for designing ITSs are categorized into eight different categories that are listed in Table V. Rule based reasoning technique was leading approach in designed ITSs. Rule based techniques increase trace of system reasoning for specific case with background familiarity [60]. This method was used in $28.21 \%$ studies to design ITSs, in computer science domain $66.66 \%$ designed ITSs were based on rule based reasoning out of which most systems were designed for programming purpose. In mathematics domain 50\% ITSs used rule based reasoning method for system designing. It seems that rule based method could be a suitable choice for decision making in computer programming fields and mathematics fields to deal with structure, patterns and numbers.

Bayesian technique was second widely used technique is designing of ITSs. These techniques based on probabilistic association between set of variables [61]. Bayesian method was used in $15.38 \%$ studies and majority of these studies were related to computer science, mathematics and physics domains. Bayesian technique is good method to deal with problems that deals with uncertainties [62]. In $12.28 \%$ studies intelligent agent systems were used in designed ITSs, intelligent agent system used to solve problems that are difficult to solve by an individual [63]. These systems were used for skill improvement, multi domain learning and problem solving in computer programming. In computing field intelligent agent techniques can be used to support its users in process of communication with system [64]. Frequency of data mining and Artificial Neural Network (ANN) techniques was almost similar.

Case based reasoning technique was least used technique in developed ITSs. This technique is usually used to solve new problems by finding most similar problem and updating the existing case according to found model [65]. However this technique was only used in two works that were related to computer programming. Case based reasoning can be beneficial in medical domain for design of tutoring systems [66]. 


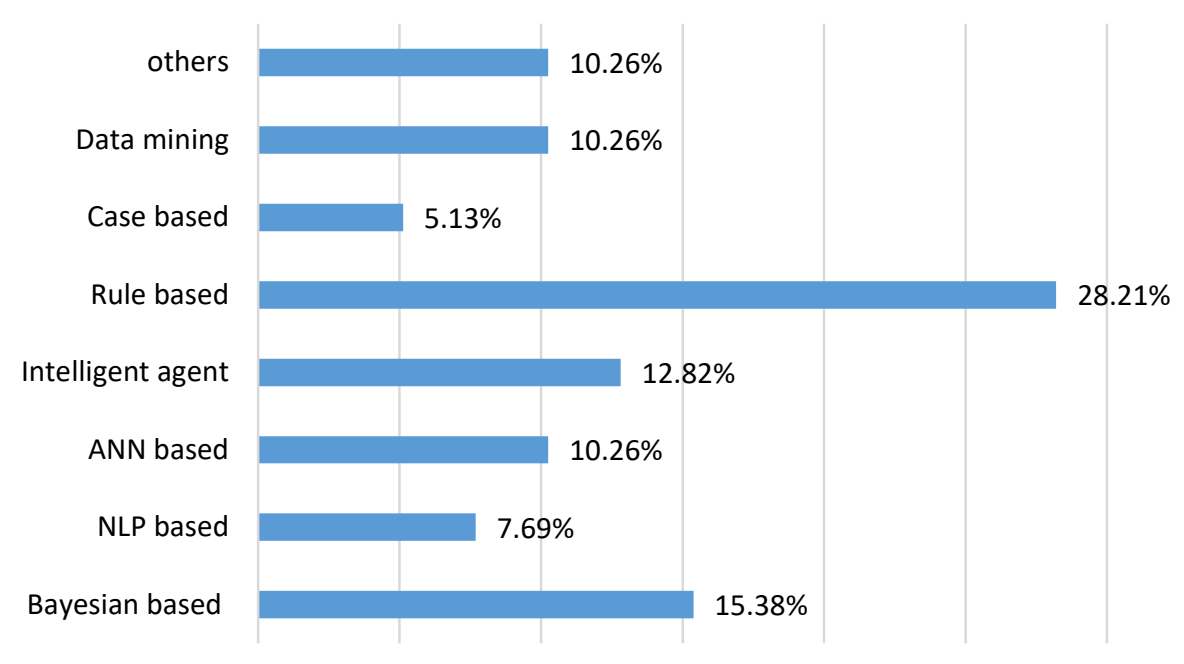

Fig. 3. Frequency of ITSs Development Techniques.

TABLE V. CATEGORY Wise RESUlTS OF QUESTION 2

\begin{tabular}{|l|l|l|}
\hline question & Techniques & No. of papers \\
\hline \multirow{4}{*}{$\begin{array}{l}\text { What type of techniques or tools } \\
\text { have been used in development } \\
\text { of ITSs? }\end{array}$} & Bayesian based & 6 \\
\cline { 2 - 3 } & NLP based & 3 \\
\cline { 2 - 3 } & ANN based & 4 \\
\cline { 2 - 3 } & Intelligent agent & 5 \\
\cline { 2 - 3 } & Rule based & 11 \\
\cline { 2 - 3 } & Case based & 2 \\
\cline { 2 - 3 } & Data mining & 4 \\
\cline { 2 - 3 } & others & 4 \\
\hline
\end{tabular}

C. What Type of Delivery Modes has been used by Developed ITSs?

The results of question 3 are presented in Table VI and frequency of ITSs delivery modes is shown in Fig. 4. These results show that web based mode was leading mode in delivering by tutoring systems. $51 \%$ of selected papers were relied on web based systems for delivering educational material to learner. In computer science domain $55.55 \%$ intelligent tutoring systems were web based. The frequency of web based tutoring systems in mathematics and medical domains were $50 \%$ and $45 \%$, respectively.

Computer based application software for intelligent tutoring was used in $30.77 \%$ studies. In mathematic domain $50 \%$ developed ITSs were computer based application software while frequency of application software in computer science and medical domain were $33.33 \%$ and $40 \%$, respectively. In $10.26 \%$ studies researchers provides a conceptual or theoretical framework for tutoring systems. While model was proposed in only one study that was related to physics domain. These results reveal the fact that web based and computer application based modes are most popular infrastructure for the development of tutoring systems.
TABLE VI. CATEgORy Wise Results OF QUESTION 3

\begin{tabular}{|l|l|l|}
\hline question & Delivery mode & No. of papers \\
\hline \multirow{4}{*}{$\begin{array}{l}\text { What type of delivery modes } \\
\text { have been used by developed }\end{array}$} & Web based systems & 20 \\
\cline { 2 - 3 } ITS? & $\begin{array}{l}\text { computer based } \\
\text { application software }\end{array}$ & 12 \\
\cline { 2 - 3 } & prototype & 2 \\
\cline { 2 - 3 } & proposed model & 1 \\
\cline { 2 - 3 } & framework & 4 \\
\hline
\end{tabular}

In our selected articles we do not found any ITSs which can provides mobile based content delivery to facilitate learner. However, mobile devices are considered as emerging technologies and its use in society is part of daily routine [67]. These devices can facilitate the implementation of tutoring systems independent of location and time [58].

\section{How the Techniques have been Validated?}

The results of question 4 are presented in Table VII and percentile results of question 4 are shown in Fig. 5. The method that was used widely for validation of the developed ITSs was experiment (59\%). In experimental validation different type of techniques were used out of which $74 \%$ experiments were performed on basis of user or learner performance in which pretest and posttest were conducted to evaluate the system. $17 \%$ experiments were based on comparative analysis between groups of ITSs users and nonusers, while remaining experimental approaches were based on learner knowledge and skills for system validation. Experimental methods were widely used in the field of computer science and medical. The frequency of these methods in computer science and medical were $61.11 \%$ and $60 \%$, respectively. 
In validation of any ITS, learner plays an important role, learner experience of using system or feedback is one of the most common method that could address the problems related to usability of specific system [68]. In this review we found only $15.38 \%$ studies in which systems were evaluated on basis of user feedback. While $10.25 \%$ studies use both experimental and feedback methods for system validation. The remaining validation method includes prototype testing, simulation and observation. Only one study in medical science domain was found in which not any kind of validation method was adopted for system evaluation.
TABLE VII. CATEGORY Wise RESUlt OF QUESTION 4

\begin{tabular}{|l|l|l|}
\hline Question & Validation method & No. of paper \\
\hline \multirow{4}{*}{$\begin{array}{l}\text { How the techniques } \\
\text { have been validated? }\end{array}$} & experiment & 23 \\
\cline { 2 - 3 } & user feedback & 6 \\
\cline { 2 - 3 } & Experiment \& user feedback & 4 \\
\cline { 2 - 3 } & Prototype testing & 3 \\
\cline { 2 - 3 } & simulation & 1 \\
\cline { 2 - 3 } & observation & 1 \\
\cline { 2 - 3 } & No. evaluation & 1 \\
\hline
\end{tabular}

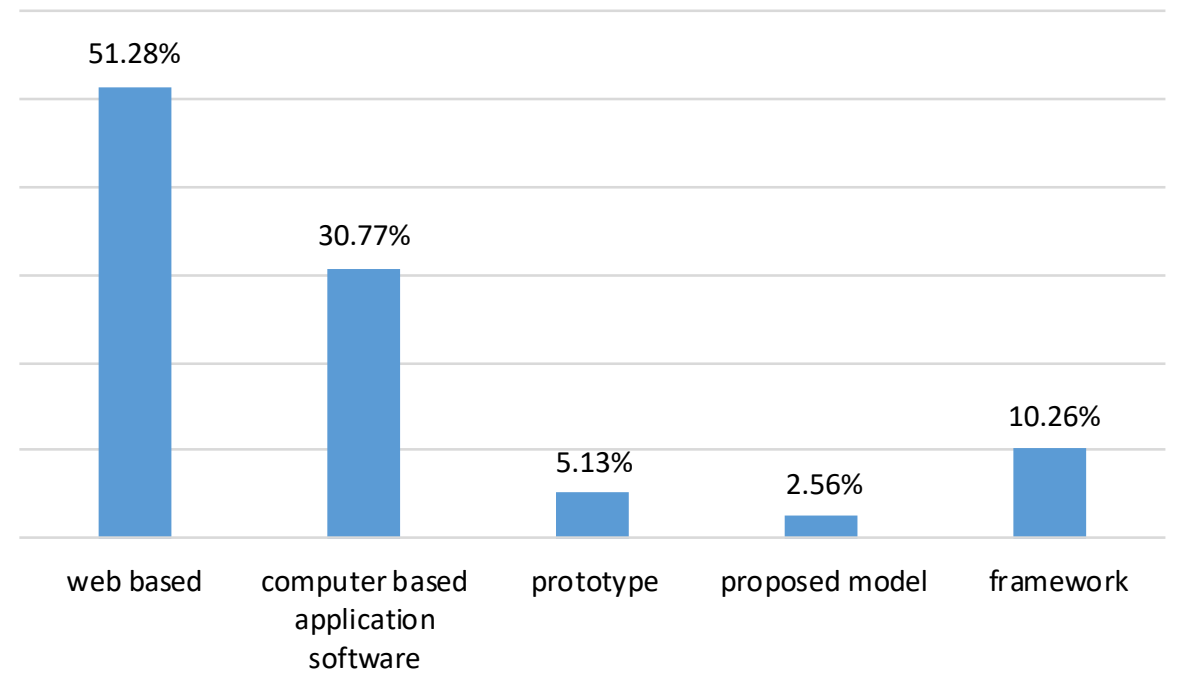

Fig. 4. Frequency of ITSs Delivery Modes.

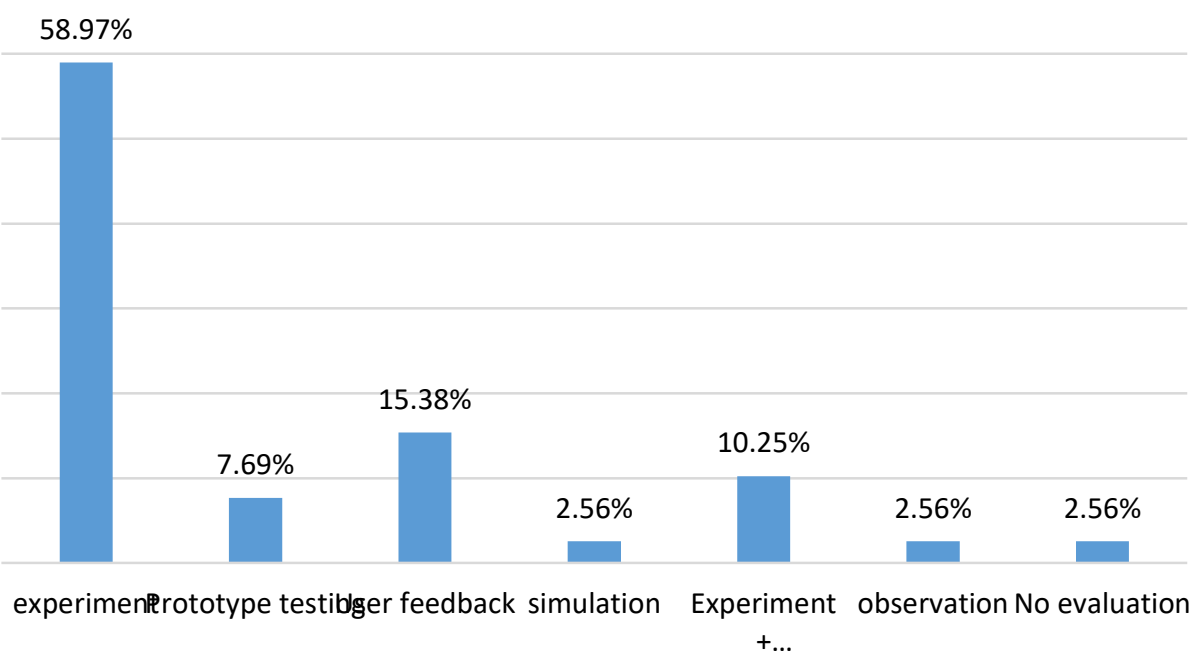

Fig. 5. Methods of Evaluation in ITSs. 


\section{CONCLUSIONS}

Intelligent Tutoring Systems have capability to replace traditional teaching method with modern adaptive teaching method in which every student get knowledge according to his/her requirement. The main feature of these systems is their ability to customize instructional strategies and activities according to learner's requirements and characteristics. In this study ITSs educational domains, purpose of ITSs in specific domain, technique for ITSs development, delivery modes of ITSs and methods of validating designed ITSs were reviewed. Computer science was a major area in which these systems were used for teaching programming subjects. Rule based and Bayesian techniques were most frequent used techniques in design of ITSs and most of the developed systems provide web based services. In addition, learner performance was major method for validation of designed system. User feedback plays important role in evaluation of any system but we found that user feedback was not considered at high level in these studies for validation of ITSs. As use of mobile devices increase, these devices can facilitate learner in personalized learning in more customized way. We also observe in this study that none of system focus on mobile based tutoring, so on the basis of this study we recommended development of mobile based ITSs.

\section{REFERENCES}

[1] P. DAŠIĆ, J. DAŠIĆ, B. CRVENKOVIĆ, and V. ŠERIFI, "A Review of Intelligent Tutoring Systems in E-Learning," Ann. Oradea UniversityFascicle of Management and Technological Engineering, vol. 15, pp. 85-90, 2016.

[2] P. Phobun and J. Vicheanpanya, "Adaptive intelligent tutoring systems for e-learning systems," Procedia-Social and Behavioral Sciences, vol. 2, pp. 4064-4069, 2010.

[3] M. C. Rosatelli and J. A. Self, "A collaborative case study system for distance learning," International Journal of Artificial Intelligence in Education, vol. 14, pp. 97-125, 2004.

[4] J. Zhang, "Intelligent tutoring systems: research status and its development in China," in Natural Language Processing and Knowledge Engineering, 2005. IEEE NLP-KE'05. Proceedings of 2005 IEEE International Conference on, 2005, pp. 683-689.

[5] M. C. Handa, "Learner-centred differentiation model: A new framework," Australasian Journal of Gifted Education, vol. 18, p. 55, 2009.

[6] C. M. Reigeluth, S. Aslan, Z. Chen, P. Dutta, Y. Huh, D. Lee, et al., "Personalized integrated educational system: Technology functions for the learner-centered paradigm of education," Journal of Educational Computing Research, vol. 53, pp. 459-496, 2015.

[7] T. Buchanan, "The efficacy of a World-Wide Web mediated formative assessment," Journal of Computer Assisted Learning, vol. 16, pp. 193200, 2000

[8] D. Hooshyar, R. B. Ahmad, M. Yousefi, M. Fathi, S.-J. Horng, and H. Lim, "SITS: a solution-based intelligent tutoring system for students' acquisition of problem-solving skills in computer programming," Innovations in Education and Teaching International, vol. 55, pp. 325335, 2018.

[9] A. Keleş, R. Ocak, A. Keleş, and A. Gülcü, "ZOSMAT: Web-based intelligent tutoring system for teaching-learning process," Expert Systems with Applications, vol. 36, pp. 1229-1239, 2009.

[10] A. M. Latham, K. A. Crockett, D. A. McLean, B. Edmonds, and K. O'Shea, "Oscar: An intelligent conversational agent tutor to estimate learning styles," in Fuzzy Systems (FUZZ), 2010 IEEE International Conference on, 2010, pp. 1-8.

[11] F. Caviglia and M. Delfino, "Foundational skills and dispositions for learning: an experience with Information Problem Solving on the Web," Technology, Pedagogy and Education, vol. 25, pp. 487-512, 2016.
[12] D. Hooshyar, R. B. Ahmad, M. Yousefi, F. Yusop, and S. J. Horng, "A flowchart-based intelligent tutoring system for improving problemsolving skills of novice programmers," Journal of Computer Assisted Learning, vol. 31, pp. 345-361, 2015.

[13] G.-J. Hwang and F.-R. Kuo, "An information-summarising instruction strategy for improving the web-based problem solving abilities of students," Australasian Journal of Educational Technology, vol. 27, 2011.

[14] D. Azcona, I.-H. Hsiao, and A. F. Smeaton, "Modelling Math Learning on an Open Access Intelligent Tutor," in International Conference on Artificial Intelligence in Education, 2018, pp. 36-40.

[15] B. P. Woolf, Building intelligent interactive tutors: Student-centered strategies for revolutionizing e-learning: Morgan Kaufmann, 2010.

[16] J. R. Carbonell, "AI in CAI: An artificial-intelligence approach to computer-assisted instruction," IEEE transactions on man-machine systems, vol. 11, pp. 190-202, 1970.

[17] W. J. Clancey, "Methodology for building an intelligent tutoring system," Methods and tactics in cognitive science, pp. 51-84, 1984.

[18] W. Ma, O. O. Adesope, J. C. Nesbit, and Q. Liu, "Intelligent tutoring systems and learning outcomes: A meta-analysis," Journal of educational psychology, vol. 106, p. 901, 2014.

[19] E. E. Carter, "An Intelligent Debugging Tutor For Novice Computer Science Students," 2014.

[20] Q. Brown, "Mobile intelligent tutoring system: moving intelligent tutoring systems off the desktop," 2009.

[21] M. C. Polson and J. J. Richardson, Foundations of intelligent tutoring systems: Psychology Press, 2013.

[22] C. C. Hugh Burns, Foundations of intelligent tutoring systems: An introduction: Texas Laboratory, 1989.

[23] P. Brereton, B. A. Kitchenham, D. Budgen, M. Turner, and M. Khalil, "Lessons from applying the systematic literature review process within the software engineering domain," Journal of systems and software, vol. 80, pp. 571-583, 2007.

[24] C. Wohlin, "Guidelines for snowballing in systematic literature studies and a replication in software engineering," in Proceedings of the 18th international conference on evaluation and assessment in software engineering, 2014, p. 38

[25] C. Walkington and M. L. Bernacki, "Personalizing Algebra to Students' Individual Interests in an Intelligent Tutoring System: Moderators of Impact," International Journal of Artificial Intelligence in Education, pp. $1-31,2018$.

[26] K. S. McCarthy, A. D. Likens, A. M. Johnson, T. A. Guerrero, and D. S. McNamara, "Metacognitive Overload!: Positive and Negative Effects of Metacognitive Prompts in an Intelligent Tutoring System," International Journal of Artificial Intelligence in Education, pp. 1-19, 2018.

[27] D. Hooshyar, R. B. Ahmad, M. Wang, M. Yousefi, M. Fathi, and H. Lim, "Development and evaluation of a game-based bayesian intelligent tutoring system for teaching programming," Journal of Educational Computing Research, vol. 56, pp. 775-801, 2018.

[28] M. Dlamini and W. S. Leung, "Enhancing Object-Oriented Programming Pedagogy with an Adaptive Intelligent Tutoring System," in Annual Conference of the Southern African Computer Lecturers' Association, 2018, pp. 269-284.

[29] M. J. Mosa, I. Albatish, and S. S. Abu-Naser, "ASP. NET-Tutor: Intelligent Tutoring System for leaning ASP. NET," 2018.

[30] H. A. Al Rekhawi and S. Abu Naser, "An Intelligent Tutoring System for Learning Android Applications Ui Development," 2018.

[31] A. Vijayan, S. Janmasree, C. Keerthana, and L. B. Syla, "A Framework for Intelligent Learning Assistant Platform Based on Cognitive Computing for Children with Autism Spectrum Disorder," in 2018 International CET Conference on Control, Communication, and Computing (IC4), 2018, pp. 361-365.

[32] R. Cole, C. Buchenroth-Martin, T. Weston, L. Devine, J. Myatt, B. Helding, et al., "One-on-one and small group conversations with an intelligent virtual science tutor," Computer Speech \& Language, vol. 50, pp. 157-174, 2018/07/01/2018.

[33] U. Kose and A. Arslan, "Optimization of self-learning in Computer Engineering courses: An intelligent software system supported by 
Artificial Neural Network and Vortex Optimization Algorithm," Computer Applications in Engineering Education, vol. 25, pp. 142-156, 2017.

[34] M. Samarakou, P. Prentakis, D. Mitsoudis, D. Karolidis, and S. Athinaios, "Application of fuzzy logic for the assessment of engineering students," in Global Engineering Education Conference (EDUCON), 2017 IEEE, 2017, pp. 646-650.

[35] R. Britto, W. G. de Oliveira Filho, C. G. Barros, and E. C. Lopes, "Intelligent tutor system model applied to basic electronics," in Information Systems and Technologies (CISTI), 2017 12th Iberian Conference on, 2017, pp. 1-5.

[36] B. Mostafavi and T. Barnes, "Evolution of an intelligent deductive logic tutor using data-driven elements," International Journal of Artificial Intelligence in Education, vol. 27, pp. 5-36, 2017.

[37] N. Bosch and S. D'Mello, "The affective experience of novice computer programmers," International Journal of Artificial Intelligence in Education, vol. 27, pp. 181-206, 2017.

[38] G. Fontaine, S. Cossette, and M. A. Maheu-Cadotte, "Development and Evaluation of an Intelligent Learning Environment for the Assessment and Management of Cardiometabolic Risk by Acute Care Nurses: A Research Protocol," Canadian Journal of Cardiology, vol. 33, p. S212, 2017/10/01/2017.

[39] Y. P. Xin, R. Tzur, C. Hord, J. Liu, J. Y. Park, and L. Si, "An intelligent tutor-assisted mathematics intervention program for students with learning difficulties," Learning Disability Quarterly, vol. 40, pp. 4-16, 2017.

[40] M. W. Alawar and S. S. A. Naser, "CSS-Tutor: An intelligent tutoring system for CSS and HTML," International Journal of Academic Research and Development, vol. 2, pp. 94-98, 2017.

[41] A. Sehrawat, R. Keelan, K. Shimada, D. M. Wilfong, J. T. McCormick, and Y. Rabin, "Simulation-based cryosurgery intelligent tutoring system prototype," Technology in cancer research \& treatment, vol. 15, pp. 396407, 2016.

[42] K. Almohammadi, H. Hagras, D. Alghazzawi, and G. Aldabbagh, "Users-centric adaptive learning system based on interval type-2 fuzzy logic for massively crowded e-learning platforms," Journal of Artificial Intelligence and Soft Computing Research, vol. 6, pp. 81-101, 2016.

[43] B. Grawemeyer, M. Mavrikis, W. Holmes, S. Gutierrez-Santos, M. Wiedmann, and N. Rummel, "Affecting off-task behaviour: how affectaware feedback can improve student learning," in Proceedings of the sixth international conference on learning analytics \& knowledge, 2016, pp. 104-113.

[44] C. R. Wolfe, V. F. Reyna, C. L. Widmer, E. M. Cedillos-Whynott, P. G. Brust-Renck, A. M. Weil, et al., "Understanding genetic breast cancer risk: Processing loci of the BRCA Gist intelligent tutoring system," Learning and individual differences, vol. 49, pp. 178-189, 2016.

[45] D. Hooshyar, R. B. Ahmad, M. Yousefi, M. Fathi, S.-J. Horng, and H. Lim, "Applying an online game-based formative assessment in a flowchart-based intelligent tutoring system for improving problemsolving skills," Computers \& Education, vol. 94, pp. 18-36, 2016/03/01/ 2016.

[46] M. I. Alhabbash, A. O. Mahdi, and S. S. A. Naser, "An Intelligent Tutoring System for Teaching Grammar English Tenses," 2016.

[47] J. M. Harley, F. Bouchet, M. S. Hussain, R. Azevedo, and R. Calvo, "A multi-componential analysis of emotions during complex learning with an intelligent multi-agent system," Computers in Human Behavior, vol. 48, pp. 615-625, 2015.

[48] K. Dolenc and B. Aberšek, "TECH8 intelligent and adaptive e-learning system: Integration into Technology and Science classrooms in lower secondary schools," Computers \& Education, vol. 82, pp. 354-365, 2015.

[49] V. Echeverria, B. Guaman, and K. Chiluiza, "Mirroring Teachers' Assessment of Novice Students' Presentations through an Intelligent Tutor System," in Computer Aided System Engineering (APCASE), 2015 Asia-Pacific Conference on, 2015, pp. 264-269.
[50] P. Mohammed and P. Mohan, "Dynamic cultural contextualisation of educational content in intelligent learning environments using ICON," International Journal of Artificial Intelligence in Education, vol. 25, pp. 249-270, 2015.

[51] D. P. Vinchurkar and M. Sasikumar, "Intelligent Tutoring System for Voice Conversion in English," in Advanced Learning Technologies (ICALT), 2015 IEEE 15th International Conference on, 2015, pp. 314316.

[52] D. Wang, H. Han, Z. Zhan, J. Xu, Q. Liu, and G. Ren, "A problem solving oriented intelligent tutoring system to improve students' acquisition of basic computer skills," Computers \& Education, vol. 81, pp. 102-112, 2015.

[53] A. Smith, W. Min, B. W. Mott, and J. C. Lester, "Diagrammatic student models: Modeling student drawing performance with deep learning," in International Conference on User Modeling, Adaptation, and Personalization, 2015, pp. 216-227.

[54] M. Dzikovska, N. Steinhauser, E. Farrow, J. Moore, and G. Campbell, "BEETLE II: Deep natural language understanding and automatic feedback generation for intelligent tutoring in basic electricity and electronics," International Journal of Artificial Intelligence in Education, vol. 24, pp. 284-332, 2014.

[55] G. A. Khachatryan, A. V. Romashov, A. R. Khachatryan, S. J. Gaudino, J. M. Khachatryan, K. R. Guarian, et al., "Reasoning Mind Genie 2: An intelligent tutoring system as a vehicle for international transfer of instructional methods in mathematics," International Journal of Artificial Intelligence in Education, vol. 24, pp. 333-382, 2014.

[56] E. Walker, N. Rummel, and K. R. Koedinger, "Adaptive intelligent support to improve peer tutoring in algebra," International Journal of Artificial Intelligence in Education, vol. 24, pp. 33-61, 2014.

[57] D. Weragama and J. Reye, "Analysing student programs in the PHP intelligent tutoring system," International Journal of Artificial Intelligence in Education, vol. 24, pp. 162-188, 2014.

[58] S. Gómez, P. Zervas, D. G. Sampson, and R. Fabregat, "Context-aware adaptive and personalized mobile learning delivery supported by UoLmP," Journal of King Saud University-Computer and Information Sciences, vol. 26, pp. 47-61, 2014.

[59] S-J. Hsieh and Y.-T. Cheng, "Algorithm and intelligent tutoring system design for programmable controller programming," The International Journal of Advanced Manufacturing Technology, vol. 71, pp. 1099$1115,2014$.

[60] W. R. Swartout, "Knowledge needed for expert system explanation."

[61] T. N. Phyu, "Survey of classification techniques in data mining," in Proceedings of the International MultiConference of Engineers and Computer Scientists, 2009, pp. 18-20.

[62] A. R. Masegosa and S. Moral, "An interactive approach for Bayesian network learning using domain/expert knowledge," International Journal of Approximate Reasoning, vol. 54, pp. 1168-1181, 2013.

[63] P. Stone and M. Veloso, "Multiagent systems: A survey from a machine learning perspective," Autonomous Robots, vol. 8, pp. 345-383, 2000.

[64] J. Psotka, L. D. Massey, and S. A. Mutter, Intelligent tutoring systems: Lessons learned: Psychology Press, 1988.

[65] M. Pantic, "Introduction to machine learning \& case-based reasoning," London: Imperial College, 2005.

[66] A. Holt, I. Bichindaritz, R. Schmidt, and P. Perner, "Medical applications in case-based reasoning," The Knowledge Engineering Review, vol. 20, pp. 289-292, 2005.

[67] L. Briz-Ponce, J. A. Juanes-Méndez, F. J. García-Peñalvo, and A. Pereira, "Effects of mobile learning in medical education: a counterfactual evaluation," Journal of medical systems, vol. 40, p. 136, 2016.

[68] C. Mulwa, S. Lawless, M. Sharp, and V. Wade, "A web-based framework for user-centred evaluation of end-user experience in adaptive and personalized e-learning systems," in Proceedings of the 2011 IEEE/WIC/ACM International Conferences on Web Intelligence and Intelligent Agent Technology-Volume 03, 2011, pp. 351-356. 